\title{
Acetate as an active metabolite of ethanol: studies of locomotion, loss of righting reflex, and anxiety in rodents
}

\author{
Marta Pardo ${ }^{1}$, Adrienne J. Betz ${ }^{2}$, Noemí San Miguel ${ }^{1}$, Laura López-Cruz ${ }^{1}$, John D. Salamone ${ }^{3}$ and \\ Mercè Correa ${ }^{1,3 *}$
}

1 Àrea de Psicobiologia, Campus Riu Sec, Universitat Jaume I, Castelló, Spain

${ }^{2}$ Department of Psychology, Quinnipiac University, Hamden, CT, USA

${ }^{3}$ Department of Psychology, University of Connecticut, Storrs, CT, USA

\section{Edited by:}

Elio Acquas, University of Cagliari, Italy

\section{Reviewed by:}

Fabrício A. Pamplona, Universidade Federal de Santa Catarina, Brazil Elio Acquas, University of Cagliari, Italy

Sergey M. Zimatkin, Grodno State Medical University, Belarus

\section{*Correspondence:}

Mercè Correa, Àrea de

Psicobiologia, Campus Riu Sec,

Universitat Jaume I, Avda. Sos

Baynat s/n, 12071 Castelló, Spain

e-mail: correa@psb.uji.es
It has been postulated that a number of the central effects of ethanol are mediated via ethanol metabolites: acetaldehyde and acetate. Ethanol is known to produce a large variety of behavioral actions such anxiolysis, narcosis, and modulation of locomotion. Acetaldehyde contributes to some of those effects although the contribution of acetate is less known. In the present studies, rats and mice were used to assess the acute and chronic effects of acetate after central or peripheral administration. Male Sprague-Dawley rats were used for the comparison between central (intraventricular, ICV) and peripheral (intraperitoneal, IP) administration of acute doses of acetate on locomotion. CD1 male mice were used to study acute IP effects of acetate on locomotion, and also the effects of chronic oral consumption of acetate $(0,500$, or $1000 \mathrm{mg} / \mathrm{l}$, during $7,15,30$, or 60 days) on ethanol- $(1.0,2.0,4.0$, or $4.5 \mathrm{~g} / \mathrm{kg}, \mathrm{IP})$ induced locomotion, anxiolysis, and loss of righting reflex (LORR). In rats, ICV acetate (0.7-2.8 $\mu$ moles) reduced spontaneous locomotion at doses that, in the case of ethanol and acetaldehyde, had previously been shown to stimulate locomotion. Peripheral acute administration of acetate also suppressed locomotion in rats $(25-100 \mathrm{mg} / \mathrm{kg})$, but not in mice. In addition, although chronic administration of acetate during 15 days did not have an effect on spontaneous locomotion in an open field, it blocked ethanol-induced locomotion. However, ethanolinduced anxiolysis was not affected by chronic administration of acetate. Chronic consumption of acetate (up to 60 days) did not have an effect on latency to, or duration of LORR induced by ethanol, but significantly increased the number of mice that did not achieve LORR. The present work provides new evidence supporting the hypothesis that acetate should be considered a centrally-active metabolite of ethanol that contributes to some behavioral effects of this alcohol, such as motor suppression.

Keywords: ataxia, anxiety, alcohol metabolism, acetaldehyde, acetate, narcosis

\section{INTRODUCTION}

Acetate is a short-chain fatty acid formed as the final step in ethanol oxidation. The oxidative metabolism of ethanol into acetaldehyde takes place in several organs, and can involve multiple enzymes, including alcohol dehydrogenase (ADH), cytochrome P450 2E1 (CYP2E1), and catalase. Acetaldehyde is then metabolized mainly by aldehyde dehydrogenase (ALDH) into acetate. Following ethanol ingestion, approximately $70 \%$ of the acetate generated through oxidative metabolism is released from the liver into systemic circulation (Busch, 1953; Van den Berg et al., 1966). Acetate can be detected in plasma after ethanol administration, because the portion that has not been metabolized hepatically is released into the blood. Acetate is then redistributed throughout the body, metabolized in extra-hepatic organs (Lundquist et al., 1962), rapidly taken up into the brain by a carrier-mediated process (Oldendorf, 1973), and also is actively metabolized in the brain (Cullen and Carlen, 1992). An alternative central source of acetate is brain ethanol metabolism. It has been demonstrated (Zimatkin et al., 2006) that pharmacological manipulations that reduce catalase activity also reduce the amount of acetate detected in rat and mice brain homogenates. Moreover, when brain homogenates from CYP2E1 KO mice where incubated with ethanol plus a catalase inhibitor, there was a significant reduction of acetate formation, an effect which was not observed in brain homogenates from catalase-deficient mice (Zimatkin et al., 2006). Pharmacological inhibition of CYP2E1 also leads to significant decreases in acetate accumulation in rat brain homogenates. Moreover, enzymatic inhibition of $\mathrm{ADH}$ and ALDH also reduced acetate levels (Zimatkin et al., 2006). These results demonstrate that acetate can be formed in the brain via ethanol metabolism and that the enzymatic systems involved in this process are some of the ones required to form acetaldehyde.

Acetate has been demonstrated to have specific effects on behavior. Peripherally administered acetate increased the time off a treadmill, a measure of motor incoordination in rats, and 
suppressed locomotion in mice (Carmichael et al., 1991; Israel et al., 1994). In fact, peripherally injected acetate has been demonstrated to be three times more potent than ethanol at suppressing locomotion in mice (Israel et al., 1994). Moreover, acetate injected peripherally or in the brain ventricles also suppressed food-reinforced lever pressing on a FR5 schedule of reinforcement, which generates high levels of performance (Arizzi et al., 2003; McLaughlin et al., 2008). Thus, it has been suggested that acetate is involved mainly in the depressant effects of ethanol (Carmichael et al., 1991; Israel et al., 1994; Arizzi et al., 2003; Correa et al., 2003). Consistent with this idea, acetate can mimic some of the motor suppressant, ataxic, or sedative effects of ethanol. For instance, general anesthesia is potentiated in a dosedependent fashion by ethanol as well as acetate (Carmichael et al., 1991; Campisi et al., 1997). Acetate seems to mediate tolerance to the loss of the righting reflex (LORR) produced by ethanol. Repeated administration of ethanol $[3.5 \mathrm{~g} / \mathrm{kg}$, intraperitoneal (IP) during 7 days] to outbred rats, resulted in tolerance to LORR induced by ethanol and to higher concentrations of acetate in different areas of the brain compared to acutely treated animals (Kiselevski et al., 2003). Moreover, higher amounts of acetate are formed in short sleeping (SS) rats, which have an inborn tolerance to the LORR induced by high doses of ethanol, relative to the long sleeping (LS) substrain (Zimatkin et al., 2011).

Because direct administration of ethanol and acetaldehyde seem to have different motor effects depending on the route of administration (for a review see Correa et al., 2012), the present experiments addressed the potential differences between peripheral and central injections of acetate on locomotor activity in rats. We also evaluated the impact of peripherally administered acetate on motor activity in mice at similar low doses. In a second group of experiments, because acetate accumulation after repeated administration of ethanol seems to mediate tolerance to LORR induced by ethanol (Kiselevski et al., 2003), we evaluated the impact of chronic consumption of acetate across multiple time periods on different behaviors modulated by an acute dose of ethanol in mice. Thus, we evaluated the impact of chronic exposure to acetate on ethanol-induced stimulation of locomotion and on ethanol-induced LORR in mice. Moreover, although acutely administered acetate has not shown to have an effect on anxiety measures in mice (Escrig et al., 2007, 2012) and rats (Correa et al., 2003), the anxiolytic actions of ethanol at low doses are well known (Correa et al., 2008). Thus, in the present study we also evaluated the impact of chronic administration of acetate on measures of anxiolysis induced by a low dose of ethanol in mice.

\section{METHODS \\ SUBJECTS}

Male Sprague-Dawley rats (Harlan Sprague-Dawley, Indianapolis, IN), were housed in a colony maintained at $23^{\circ} \mathrm{C}$ with lights on from 7:00 to $19: 00 \mathrm{~h}$. Animals weighed between 350 and $430 \mathrm{~g}$ at the time of the experiment. These animals had ad libitum access to food and water in their home cages. Before the test day, rats were allowed 2 weeks to acclimate to laboratory conditions, plus 1 week of being handled by the experimenter for $5 \mathrm{~min}$ each day. For the IP study, a total of 43 rats ( $n=8-9$ per group) were used and for the intraventricular (ICV) study the number was 38 ( $n=8-10$ per group).

CD1 male mice (30-40g) were purchased from HarlanInterfauna Iberica S.A. (Barcelona, Spain). Mice 6-7 weeks old at the beginning of experiments were housed in groups of three per cage, with standard laboratory rodent chow and tap water available ad libitum. They were maintained in the colony at $22 \pm 1^{\circ} \mathrm{C}$ with lights on from 8:00 to $20: 00 \mathrm{~h}$. Mice were handled and habituated to the test room for 1 week before tests were conducted. For the acute acetate study, 42 mice were used ( $n=10-11$ per group). For the chronic acetate studies, the locomotion experiment included 78 mice ( $n=8-9$ per group), the anxiety experiment included a total of 63 mice $(n=10-11$ per group), and for the LORR experiments the total number was 218 ( $n=14$ per group).

All experimental procedures were approved by the Institutional Animal Care and Use Committee, and complied with the European Community Council directive (86/609/ECC) for the use of laboratory animal subjects and with the "Guidelines for the Care and Use of Mammals in Neuroscience and Behavioral Research" (National Research Council, 2003).

\section{DRUGS AND SELECTION OF DOSES}

Anhydrous sodium acetate (hereafter referred to as acetate, Fisher Scientific) was dissolved in physiological saline for the IP studies, in artificial cerebrospinal fluid (aCSF) for the ICV studies, and in tap water for the oral chronic studies. These vehicles serve as the control solutions. For IP injections, acetate $10 \% \mathrm{w} / \mathrm{v}$ was used as the stock solution from which the different doses were obtained. ICV acetate doses of $0.7,1.4$, or $2.8 \mu$ moles $(0.0,42.03,84.07$, or $168.14 \mu \mathrm{g}$ ), were administered in $1.0 \mu \mathrm{l}$ total volume. Chronically administered acetate was prepared dissolving sodium acetate in tap water. Concentration of the solutions were 500 or $1000 \mathrm{mg} / \mathrm{l}$. After recording fluid intake and body weight per animal for 60 days, we calculated that the average dose of acetate consumed for the group exposed to $500 \mathrm{mg} / \mathrm{l}$ was $29.9 \pm 5.3 \mathrm{mg} / \mathrm{kg}$ and for the $1000 \mathrm{mg} / \mathrm{l}$ group was $67.6 \pm 1.8 \mathrm{mg} / \mathrm{kg}$. Ethanol $(96 \% \mathrm{v} / \mathrm{v}$, Panreac Quimica S. A.) was dissolved in physiological saline in a $20 \% \mathrm{v} / \mathrm{v}$ solution used as the stock solution from which the different doses were obtained. Hydrochloric acid ( $1 \mathrm{~N}$, Panreac Quimica S. A.) was used to bring the sodium acetate solutions for the acute studies to $\mathrm{pH}$ 7.4. Xylazine and Ketamine were purchased from Phoenix Pharmaceutical, Inc. (St. Joseph, Mo).

The selection of doses and times was based on pilot studies and on previous studies from our laboratory (Arizzi et al., 2003; Arizzi-LaFrance et al., 2006; Correa et al., 2003; Escrig et al., 2012).

\section{SURGICAL PROCEDURE AND ICV INJECTIONS}

For the ICV study, rats were implanted with unilateral guide cannulae (10.0 mm length, 23 ga.). Rats were anesthetized with a solution $(1.0 \mathrm{ml} / \mathrm{kg}, \mathrm{IP})$ that contained Ketamine $(100 \mathrm{mg} / \mathrm{ml})$ and Xylazine $(20 \mathrm{mg} / \mathrm{ml})$. The stereotaxic coordinates for the cannulation into the lateral ventricle were as follows: AP $-0.5 \mathrm{~mm}$ (from bregma), DL $+1.3 \mathrm{~mm}$ lateral (from midline), and DV $-3.0 \mathrm{~mm}$ ventral (from the surface of the skull). The incisor bar on the stereotax was set to $0.0 \mathrm{~mm}$ above the interaural line. All 
animals were single housed following surgery, and were allowed to recover for 7-10 days before behavioral testing. Stainless steel stylets were kept in each guide cannulae to maintain its integrity.

ICV injections were made via 30 ga. stainless steel injection cannulae extending $1.5 \mathrm{~mm}$ below the guide cannulae. The injectors were attached to $10.0 \mu \mathrm{l}$ Hamilton syringes by PE-10 tubing, and were driven by a syringe pump (Harvard Apparatus) at a rate of $0.5 \mu \mathrm{l} / \mathrm{min}$ for a total volume of $1.0 \mu \mathrm{l}$. Following the infusion period the injectors were left in place for $1 \mathrm{~min}$ to allow for diffusion of the drug, after which the injectors were removed, stylets were replaced, and animals were immediately placed into the behavioral chambers for testing.

\section{HISTOLOGY}

For the ICV experiments, the placements of the injectors were verified histologically. After the experiments were completed, all animals were intracardially perfused with heparinized physiological saline. Brains were stored refrigerated in 3.7\% formaldehyde solution for at least 5 days prior to slicing. Consecutive 50 micron sections through the relevant brain areas were collected, mounted on slides, and stained with cresyl violet solution to aid in detection of the injector tracts. Coverslipped slides were viewed microscopically to assess accuracy of implantation. Any animal with improper placement, or significant damage around the injection site, was not included in the statistical analyses of behavioral data. A total of 5 animals were rejected due to bad placements.

\section{APPARATUS AND BEHAVIORAL PROCEDURE IN RATS Enclosed stabilimeter}

Locomotor testing was performed in an automated activity chamber $(28 \times 28 \times 28 \mathrm{~cm})$, which was inside a sound-proof shell. The floor of the chamber consisted of two moveable wire mesh panels $(27 \times 13 \mathrm{~cm})$ mounted $6.0 \mathrm{~cm}$ above the chamber floor on a center rod attached at either end to the sides of the chamber; this allowed for slight vertical movement of the floor panels. Movement of the panels was detected by microswitches mounted outside the chamber at the ends of the panels. A depression of a given quadrant (quadrant $=1 / 2$ of each panel) would close the circuit on the microswitch attached to the panel. Each microswitch closure was counted as a single activity count, and activity counts were recorded by a computer in $10 \mathrm{~min}$ intervals. Rats were habituated to the chamber and to injections prior to the drug test. This was done to decrease activational effects due to novelty on the test day. On the test day, animals were placed into the activity chamber immediately after IP injections, and for the ICV studies they were placed in the chambers after $1 \mathrm{~min}$ to allow for diffusion of the drug, as described above. Locomotion was recorded in 10 min periods. In the ICV studies, after drug injections animals were anesthetized and perfused as described above, and histological analyses of brain sections were performed.

\section{APPARATUS AND BEHAVIORAL PROCEDURES IN MICE Enclosed activity box}

The enclosed locomotion chamber was made of polypropylene and consisted of a square white box divided in two compartments $(25 \mathrm{~cm} W \times 25 \mathrm{~cm} \mathrm{H} \times 22 \mathrm{~cm} \mathrm{~L})$, covered with a translucent ceiling. The behavioral test room was illuminated with a soft red light, and external noise was attenuated. As in the stabilimeter, this enclosed two-compartment box was used in order to minimize anxiogenic stimulation of locomotion. Mice were habituated to the chamber and to injections prior to the drug test. This was done to decrease activational effects due to novelty on the test day. Acetate IP was injected $10 \mathrm{~min}$ before test started. Locomotion was recorded for $10 \mathrm{~min}$. An activity count was registered by a trained observer, unaware of the experimental condition, each time the animal crossed from one quadrant to another with all four legs.

\section{Open Field (OF)}

The OF arena consisted of a Plexiglass cylinder with translucent walls $(30 \mathrm{~cm}$ in diameter and $30 \mathrm{~cm}$ high) and an opaque floor divided into four equal quadrants by two intersecting lines. Mice were handled repeatedly and habituated to the test room before the behavioral test, but were not pre-exposed to the OF. On the test day, ethanol $(1.0$ or $2.0 \mathrm{~g} / \mathrm{kg}$ ) or saline were administered acutely IP and animals were placed immediately in the OF and locomotor observations started $10 \mathrm{~min}$ later. The behavioral test room was illuminated with a soft light, and external noise was attenuated. An activity count was registered by a trained observer, unaware of the experimental condition, each time the animal crossed from one quadrant to another with all four legs.

\section{Dark-light box}

The apparatus consisted of a polypropylene chamber divided in two compartments by a partition containing a small opening $(5 \mathrm{~cm} H \times 5 \mathrm{~cm} \mathrm{~W})$. The light compartment $(25 \mathrm{~cm} \mathrm{W \times 25 \textrm {cm }}$ $H \times 25 \mathrm{~cm} L$ ) was open, painted in white, and illuminated, while the dark compartment $(25 \mathrm{~cm} W \times 25 \mathrm{~cm} H \times 18 \mathrm{~cm} \mathrm{~L})$ was painted in black and enclosed by a removable ceiling. This anxiety paradigm measures the avoidance that rodents show to bright open spaces. Several parameters were recorded during $5 \mathrm{~min}$ testing sessions. The dependent variables were: latency for the first entry into the bright compartment from the dark one, latency to go back to the dark compartment, total time spent in the bright compartment, and total crosses between compartments. In the acute study, acetate IP was injected 10 min before the dark-light box test.

\section{LORR}

Test of latency and duration of LORR were recorded consecutively. Ethanol ( 4.0 or $4.5 \mathrm{~g} / \mathrm{kg}$ ) was injected IP, and immediately mice were individually placed in a plexiglass cage. The latency was defined as the time elapsed between ethanol injection and LORR. Mice that did not lose righting reflex were not included in the posterior measurements. After mice lost the righting reflex, they were put on their back in a V-shape bed. The duration of LORR was defined as the time elapsed from LORR to the time that righting reflex was regained. Recovery was determined when mice could right themselves twice in 1 min after being placed on their backs. All the animals recovered the righting reflex. The behavioral room was illuminated with a soft light and external noise was attenuated.

These parameters were chosen based on previous studies (Correa et al., 1999, 2001, 2003, 2008; Arizzi-LaFrance et al., 2006; Chuck et al., 2006; Escrig et al., 2012). 


\section{STATISTICAL ANALYSIS}

All the experiments used a between-groups design, with each animal only being tested once. Data were analyzed by simple analysis of variance (ANOVA). If there was a significant overall drug effect, the LSD was used to make planned comparisons between each dose and the respective vehicle control condition. A computerized statistical program was used to analyze these data (SPSS 10.0).

\section{RESULTS}

\section{EXPERIMENT 1: EFFECT OF ACUTE CENTRAL OR PERIPHERAL} ADMINISTRATION OF ACETATE ON LOCOMOTOR ACTIVITY IN RATS

Figure 1A shows the effect of ICV acetate administration (0.0, $0.7,1.4$, or $2.8 \mu$ moles) on locomotor activity in the stabilimeter. Because the pattern of results was the same in the two time periods registered and there was no interaction, separate ANOVAs were performed for the two periods. The One-Way ANOVA for the $0-10$ period showed a statistically significant overall treatment effect $\left[F_{(3,22)}=7.82, p<0.01\right]$. Planned comparisons showed all doses of acetate were significantly different from vehicle $(0.7$ and $2.8 \mu$ moles $p<0.01$, and $1.4 \mu$ moles $p<0.05)$. The same pattern of results were found for the ANOVA of the second period $\left[F_{(3,22)}=8.47, p<0.01\right]$. The data for the effect of IP acetate administration $(0,12.5,25$, 50 , or $100 \mathrm{mg} / \mathrm{kg}$ ) on locomotor activity in the stabilimeter were analyzed in the same way (see Figure 1B). The OneWay ANOVA for the first period of time showed a significant effect of the peripheral dose of acetate $\left[F_{(4,36)}=4.90\right.$, $p<0.01]$, and the planned comparisons showed that the three highest doses were significantly different from vehicle $(p<$ $0.01)$. The same results were shown for the second period of time; $10-20 \min \left[F_{(4,36)}=4.86, p<0.01\right]$, and for the planned comparisons.

\section{EXPERIMENT 2: EFFECT OF ACUTE IP ADMINISTRATION OF ACETATE} ON LOCOMOTOR ACTIVITY IN MICE

The one-way factorial ANOVA for the effect of acetate treatment $(0,50,100$, or $200 \mathrm{mg} / \mathrm{kg})$ did not show significant effects on the number of crossings between the two compartments of the enclosed box $\left[F_{(3,38)}=0.63\right.$, n.s. $]$. These data are shown in Figure 2 .

\section{EXPERIMENT 3: EFFECT OF 15 DAYS OF ORAL CONSUMPTION OF ACETATE ON ETHANOL-INDUCED LOCOMOTION IN MICE}

A two-way factorial ANOVA (concentration of acetate $\times$ dose of ethanol) showed no effect of the acetate concentration factor

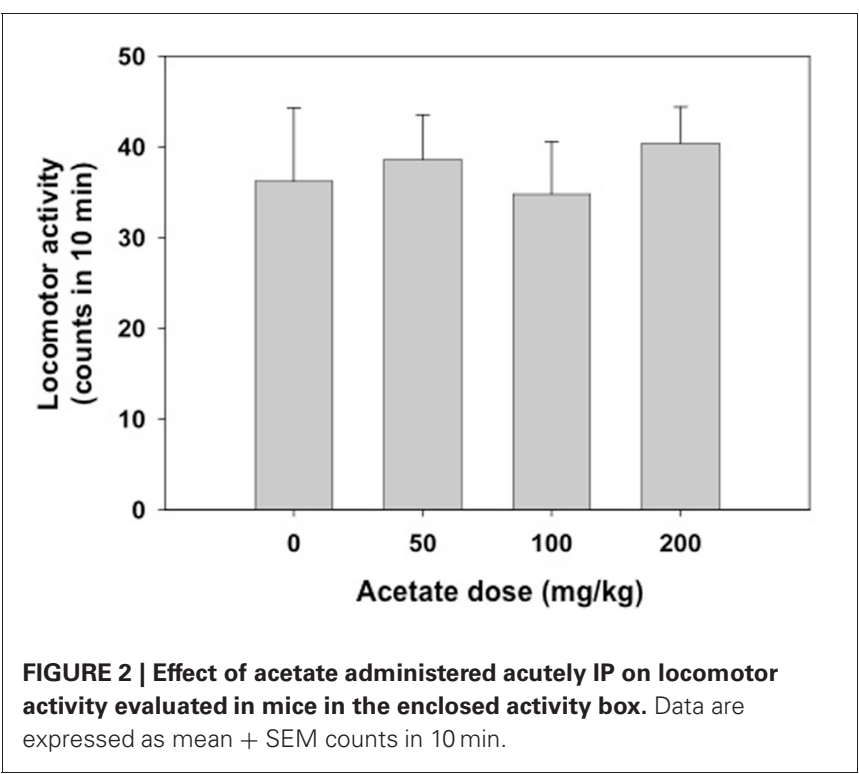

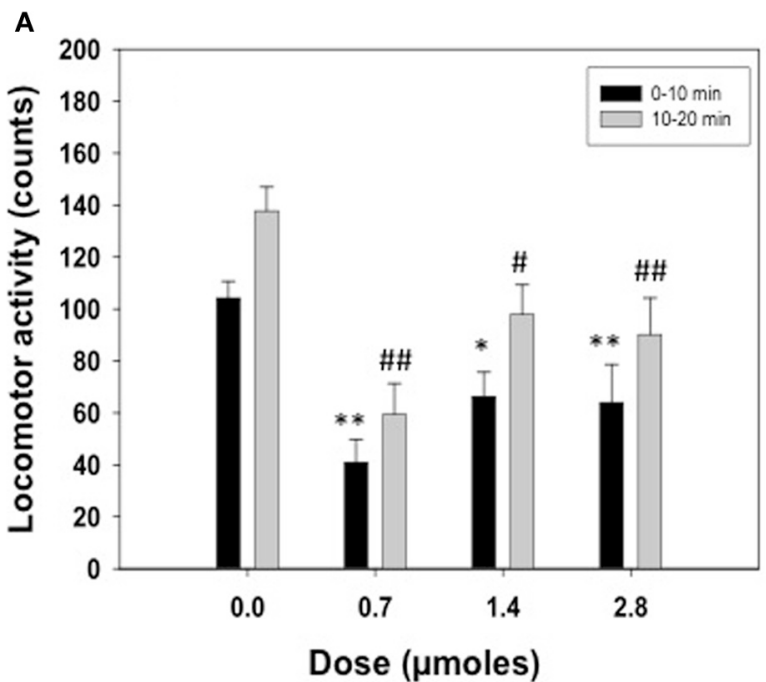

FIGURE 1 | Effect of acetate administered acutely ICV (A) or IP (B) on locomotor activity evaluated in rats in the enclosed stabilimeter. Data are expressed as mean + SEM counts in $10 \mathrm{~min}$
B

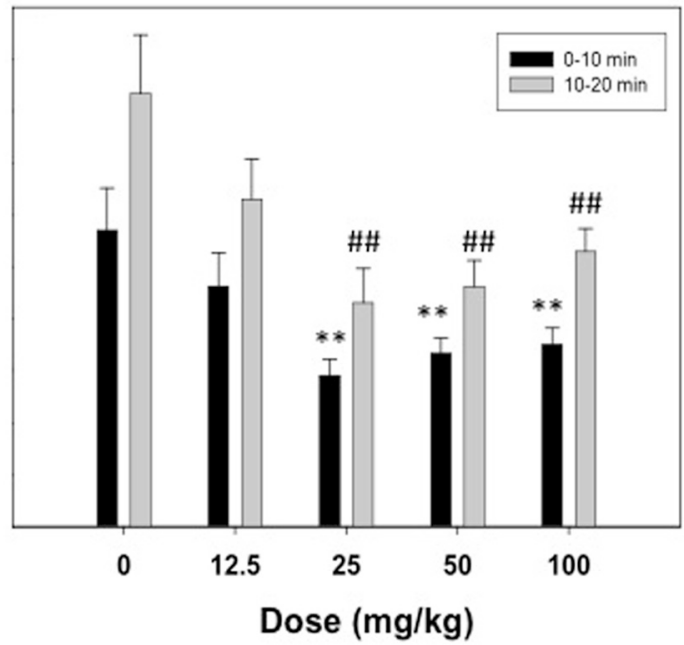

periods. ${ }^{* *} p<0.01, * p<0.05$ different from vehicle in the $0-10 \mathrm{~min}$ period. ${ }^{\# \#} p<0.01,{ }^{\#} p<0.05$ different from vehicle in the $10-20 \mathrm{~min}$ period. 
$\left[F_{(2,69)}=1.42\right.$, n.s. $]$, but a significant effect of the ethanol dose factor $\left[F_{(2,69)}=9.50, p<0.01\right]$, and a significant interaction $\left[F_{(4,69)}=2.76, p<0.05\right]$. Planned comparison revealed that the two doses of ethanol significantly induced locomotion $(1.0 \mathrm{~g} / \mathrm{kg}$ $p<0.05$ and $2.0 \mathrm{~g} / \mathrm{kg} p<0.01)$ compared to vehicle in the waterconsuming group. Moreover, these differences disappeared in the acetate consuming groups. These results are depicted in Figure 3.

\section{EXPERIMENT 4: EFFECT OF 15 DAYS OF ORAL CONSUMPTION OF ACETATE ON ETHANOL-INDUCED ANXIOLYSIS IN MICE}

The four dependent variables (see Table 1) were analyzed independently. A two-way factorial ANOVA (concentration of acetate $\times$ dose of ethanol) was performed in every case. The results of the ANOVA for the dependent variable latency to enter the bright compartment showed that there was a significant effect of the ethanol dose $\left[F_{(1,57)}=4.72, p<0.05\right]$, but no effect of the acetate treatment $\left[F_{(2,57)}=0.36\right.$, n.s. $]$, and no significant interaction $\left[F_{(2,57)}=0.57\right.$, n.s. $]$. The same pattern of results for the dependent variable latency to come back to the dark compartment was found: ethanol dose $\left[F_{(1,57)}=5.32, p<0.05\right]$, the concentration of acetate $\left[F_{(2,57)}=0.46\right.$, n.s. $]$, and the interaction

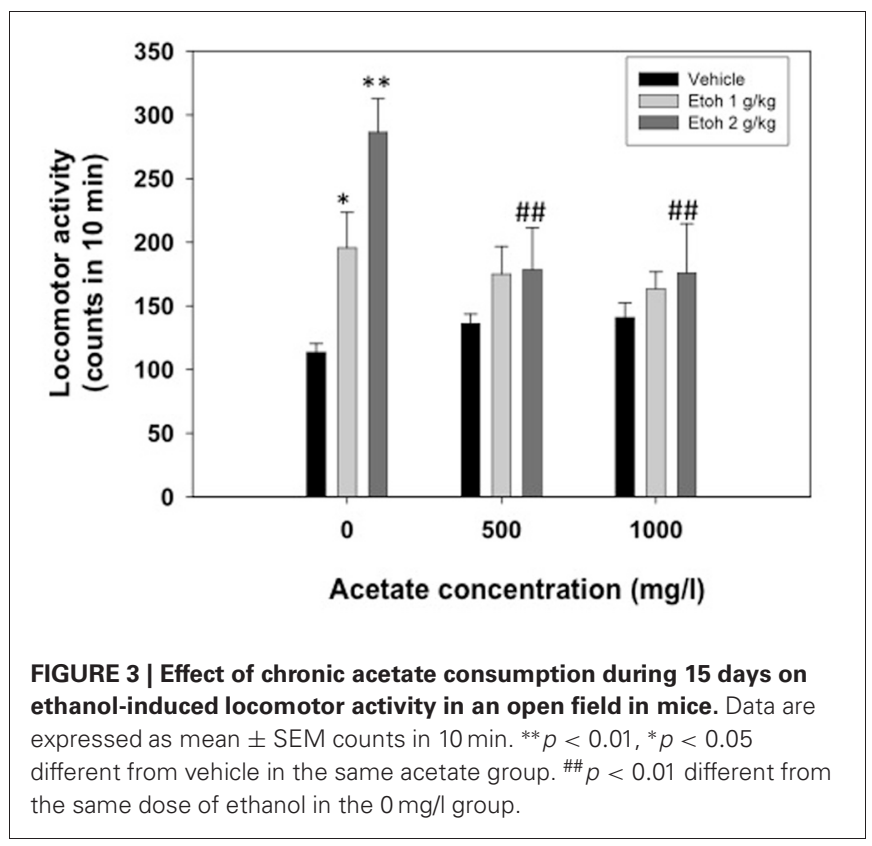

$\left[F_{(2,57)}=0.78\right.$, n.s. $]$. These results demonstrate that ethanol had an anxiolytic effect independently of the acetate treatment. The results for the total time in the bright compartment showed no significant effect: ethanol dose $\left[F_{(1,57)}=2.67\right.$, n.s. $]$, acetate treatment $\left[F_{(2,57)}=0.82\right.$, n.s. $]$, and the interaction $\left[F_{(2,57)}=0.68\right.$, n.s.]. The frequency of crossings between the bright and the dark compartments showed a marginally non-significant effect of the ethanol factor $\left[F_{(1,57)}=3.28, p=0.07\right]$, a significant effect of the acetate treatment $\left[F_{(2,57)}=3.53, p<0.05\right]$, but no significant interaction $\left[\mathrm{F}_{(2,57)}=0.52\right.$, n.s. $]$.

\section{EXPERIMENT 5: EFFECT OF ORAL CONSUMPTION OF ACETATE DURING DIFFERENT PERIODS OF TIME ON ETHANOL-INDUCED LORR IN MICE}

Animals received ethanol only once and different measures were assessed. We observed that the lower dose of ethanol $(4.0 \mathrm{~g} / \mathrm{kg})$ did not produce LORR in some animals that were immediately excluded from the following measures in this experiment (they are not included in the latency and duration analyses). Grouping together the number of animals in the three treatment groups (water, 500 and $1000 \mathrm{mg} / \mathrm{l}$ ) independently of how many days they had consumed acetate $(15,30$, or 60 days, there were no animals in the 7 days groups), the $\chi^{2}$ test for independence showed a significant effect of the acetate treatment $\left(\chi^{2}=\right.$ $10.64, d f=2, p<0.01)$. These data are depicted as percentage of animals not achieving LORR in every treatment group in Figure 4.

Among the animals that did achieve LORR, a two-way factorial ANOVA (concentration of acetate $\times$ time of consumption) for the latency to reach LORR measure yielded no significant effect of acetate concentration $\left[F_{(2,163)}=0.54\right.$, n.s. $]$, no effect of time of consumption $\left[F_{(3,163)}=1.48, n . s\right]$, and no interaction $\left[F_{(6,163)}=0.79\right.$, n.s.]. The factorial ANOVA for duration of LORR demonstrate no effect of the acetate concentration $\left[F_{(2,163)}=0.07\right.$, n.s. $]$, but a significant effect of the time of consumption $\left[F_{(3,163)}=14.28, p<0.01\right]$. However, the interaction was not significant $\left[F_{(6,163)}=0.20\right.$, n.s. $]$. Thus, $4.0 \mathrm{~g} / \mathrm{kg}$ ethanol produced an increase in duration of LORR in older animals independently of the acetate treatment. The data for the higher dose of ethanol $(4.5 \mathrm{~g} / \mathrm{kg})$ in animals consuming acetate during 60 days were analyzed separately by means of a One-Way ANOVA. The results show no effect of the concentration on either the latency $\left[F_{(2,40)}=0.43\right.$, n.s. $]$, or the duration of $\operatorname{LORR}\left[F_{(2,40)}=0.62\right.$, n.s. $]$. These data are presented in Figures 5A,B.

Table 1 | Effect of chronic acetate consumption during 15 days on vehicle or ethanol $(1 \mathrm{~g} / \mathrm{kg}$, IP) treated mice in measures of anxiety in the dark/light box.

\begin{tabular}{|c|c|c|c|c|c|c|c|c|}
\hline \multirow[t]{2}{*}{ Acetate (mg/l) } & \multicolumn{2}{|c|}{ Latency to lit compartment } & \multicolumn{2}{|c|}{$\begin{array}{l}\text { Latency to go back to } \\
\text { dark compartment }\end{array}$} & \multicolumn{2}{|c|}{ Time in lit compartment } & \multicolumn{2}{|c|}{$\begin{array}{l}\text { Number of crossings into the } \\
\text { lit compartment }\end{array}$} \\
\hline & Veh & EtOH & Veh & EtOH & Veh & EtOH & Veh & EtOH \\
\hline 0 & $11.6 \pm 1.8$ & $9.4 \pm 1.6$ & $6.6 \pm 1.9$ & $14.6 \pm 2.9$ & $105.9 \pm 10.9$ & $122.8 \pm 14.5$ & $27.7 \pm 3.1$ & $30.8 \pm 3.7$ \\
\hline 500 & $11.2 \pm 1.9$ & $6.6 \pm 1.5$ & $7.5 \pm 1.8$ & $9.6 \pm 1.4$ & $128.2 \pm 10.6$ & $129.3 \pm 6.6$ & $27.2 \pm 3.3$ & $37.4 \pm 2.8$ \\
\hline 1000 & $15.3 \pm 6.5$ & $7.2 \pm 1.3$ & $8.7 \pm 1.4$ & $12.4 \pm 3.2$ & $110.0 \pm 11.2$ & $137.1 \pm 11.6$ & $37.2 \pm 4.8$ & $40.8 \pm 4.1$ \\
\hline
\end{tabular}

Data are expressed as the mean \pm SEM seconds or counts in $5 \mathrm{~min}$. 
EXPERIMENT 6: EFFECT OF ORAL CONSUMPTION OF ACETATE DURING DIFFERENT PERIODS OF TIME ON VOLUME OF WATER CONSUMED AND BODY WEIGHT GAIN

Results from the evolution of body weight and fluid intake in animals for experiment 5 are shown in Figures 6A,B. The Two-Way ANOVA for the body weight was analyzed with a within factor for duration of treatment and a between factor for concentration of acetate. There was a significant effect of the duration $\left[F_{(4,960)}=\right.$ $437.5, p<0.01]$, but no effect of concentration $\left[F_{(2,10)}=0.40\right.$,

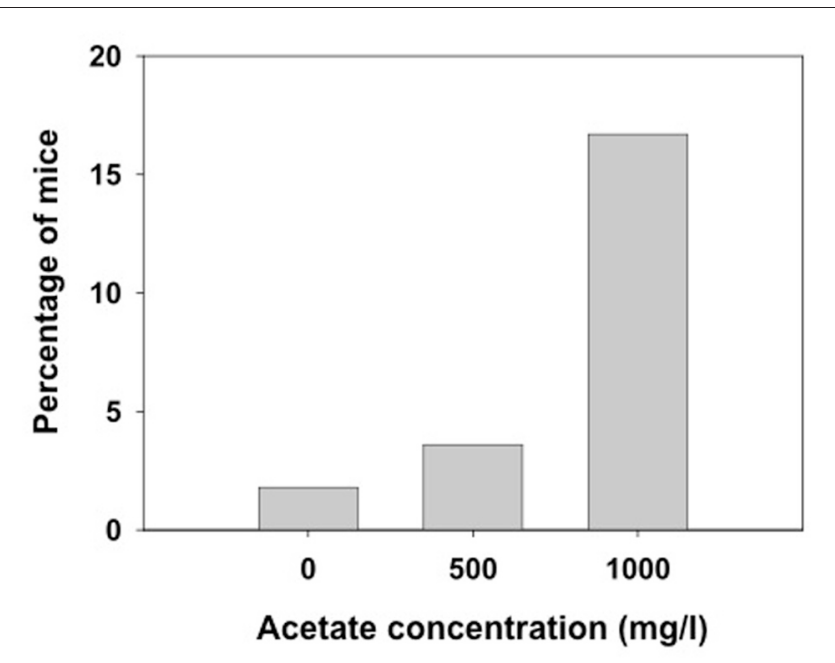

FIGURE 4 | Percentage of mice exposed to different concentrations of acetate that did not achieve LORR after receiving $4.0 \mathrm{~g} / \mathrm{kg}$ ethanol IP. n.s.], and no significant interaction $\left[F_{(8,2)}=0.84\right.$, n.s. $]$. The same pattern of results was shown for the fluid intake variable. The Two-Way ANOVA showed a significant effect of the duration $\left[F_{(4,11)}=15.43, p<0.01\right]$, but no effect of concentration $\left[F_{(2,10)}=0.11\right.$, n.s. $]$, and no significant interaction $\left[F_{(8,1)}=\right.$ 0.58, n.s.].

\section{DISCUSSION}

Studies of the behavioral effects of the ethanol metabolite acetaldehyde have been increasing in number, especially during the last decade; as a result, our knowledge of acetaldehyde's behavioral and neurochemical effects is quite comprehensive (for a recent review see Correa et al., 2012). However, acetate has remained mostly unknown, and only a handful of studies have addressed its behavioral and neurochemical actions (Israel et al., 1994; Correa et al., 2003; Kiselevski et al., 2003; Arizzi-LaFrance et al., 2004; McLaughlin et al., 2008; Zimatkin et al., 2011; Escrig et al., 2012). The present results demonstrate that acute low doses of acetate administered peripherally or into the ventricles reduce spontaneous locomotion in rats at least during $20 \mathrm{~min}$ (see Figures 1A,B). The present studies measured locomotion in small and enclosed stabilimeter cages. Centrally administered acetate (ICV) has also been shown to produce locomotor suppressant effects in rats in an open field arena (Correa et al., 2003). In that case acetate produced a monotonic decrease in activity (1.4 and $2.8 \mu$ moles) marked by significant decreases in locomotion as well as rearing (Correa et al., 2003). The suppression is more efficacious when using the small stabilimeter cages $(0.7 \mu$ moles also suppressed locomotion), possibly because this device is less anxiogenic than the open field, and therefore induces a higher level of locomotion.

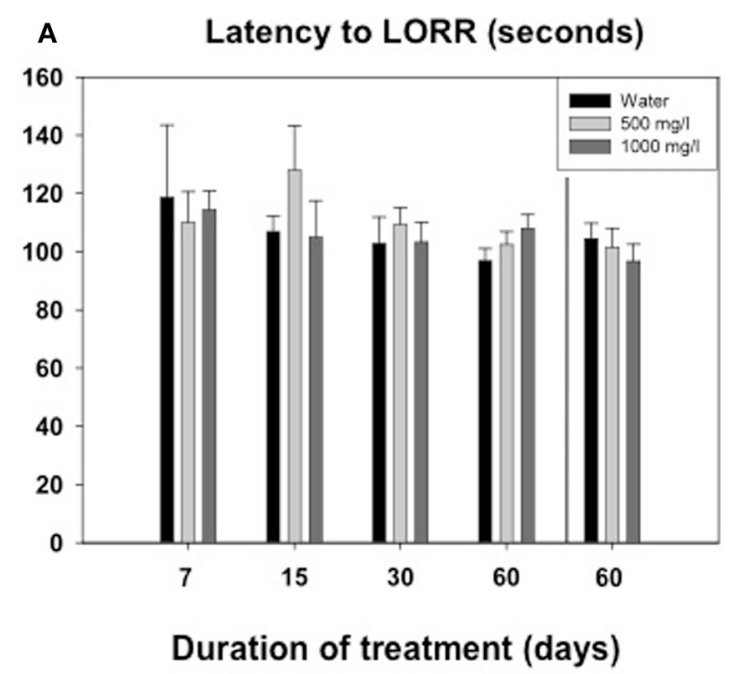

4.0

4.5

Dose of Ethanol $(\mathrm{g} / \mathrm{kg})$
B Duration of LORR (seconds)

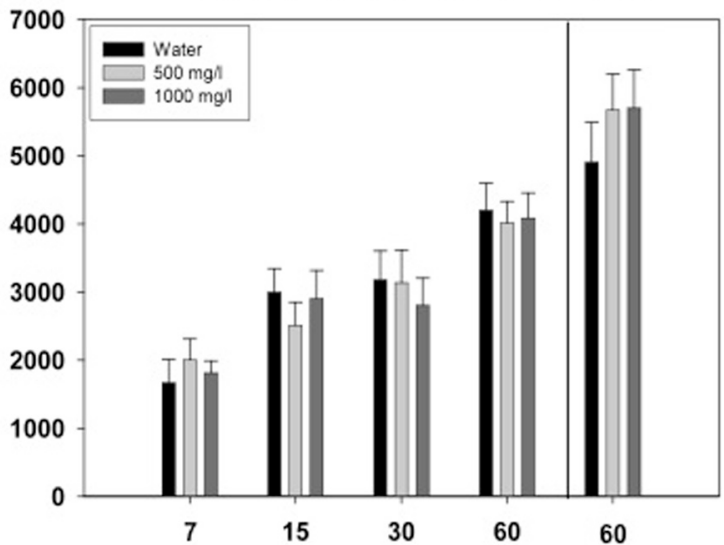

Duration of treatment (days)

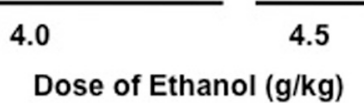

FIGURE 5 | Effect of chronic acetate consumption during different periods of time on latency (A) and duration (B) to LORR induced by an acute administration of ethanol (4.0 or $\mathbf{4 . 5} \mathbf{~ g / k g}$, IP). Data are expressed as mean \pm SEM of time in seconds. 

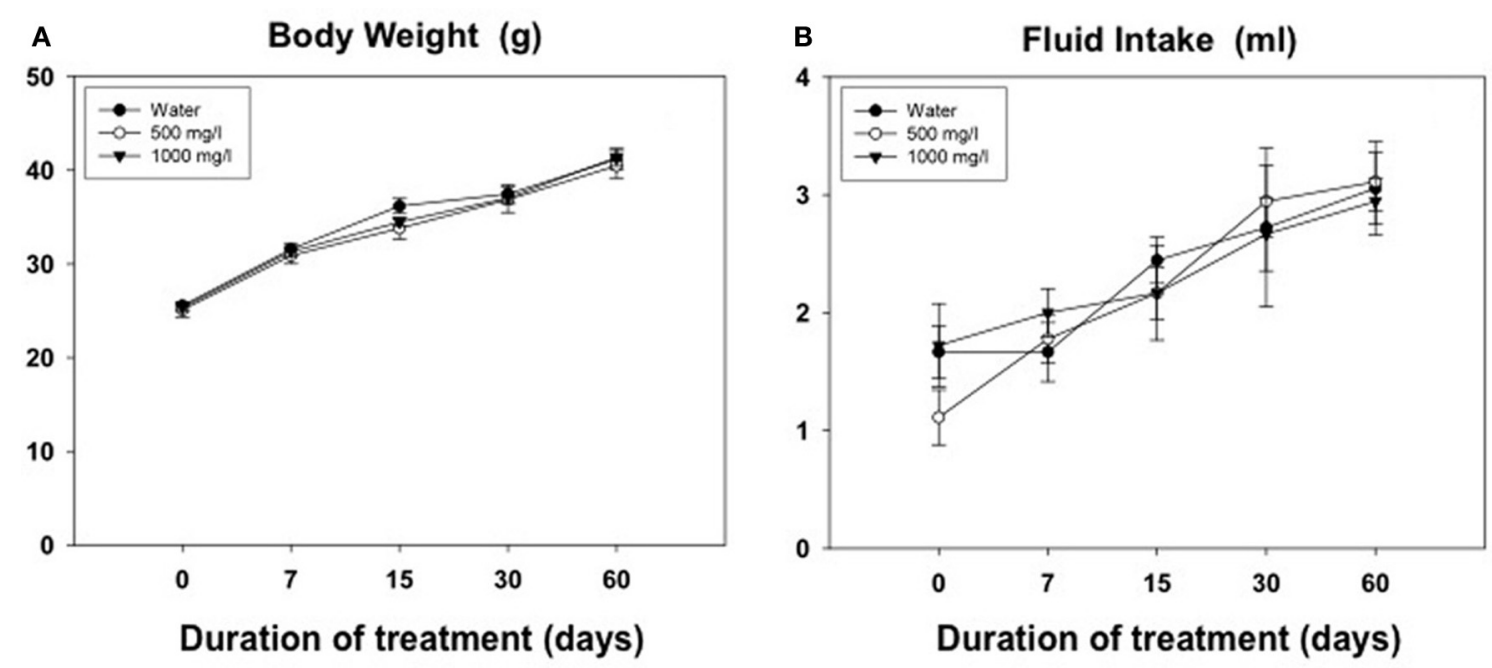

FIGURE 6 | Evolution of body weight $(\mathrm{g})(\mathrm{A})$ and volume of fluid consumed $(\mathrm{ml})(\mathrm{B})$ in animals exposed for 60 days to different concentrations of acetate. Mean \pm SEM of grams.

Rats seem to be more sensitive than mice to the suppressant effects of peripherally administered ethanol and acetate. Thus, in the present studies acetate doses between 25 and $100 \mathrm{mg} / \mathrm{kg}$ reduced locomotion in rats but not in mice; even the dose of $2.0 \mathrm{mg} / \mathrm{kg}$ did not suppress locomotion in mice under the present conditions (enclosed activity box); this dose is much lower than doses used in previous studies in mice (Israel et al., 1994). In mice the minimal dose of acetate effective for suppressing locomotion in an open field was $1.0 \mathrm{~g} / \mathrm{kg}$, while the dose of ethanol was $3.0 \mathrm{~g} / \mathrm{kg}$ (Israel et al., 1994). Thus, acetate seems more potent than ethanol at suppressing locomotion. This difference in drug potency has also been observed in other studies in rats. When injected peripherally, acetate was more potent than ethanol or acetaldehyde for suppressing foodreinforced operant responding (Arizzi et al., 2003; McLaughlin et al., 2008), reducing the number of fast responses and increasing the number of pauses that the animals took during the operant session at doses of 200-400 mg/kg, IP (McLaughlin et al., 2008). Injected into the ventricles, acetate suppressed lever pressing (2.8 and $5.6 \mu$ moles $)$, and also increased the number of pauses at the highest concentration $(5.6 \mu$ moles; McLaughlin et al., 2008), while ethanol and acetaldehyde did not. Moreover, acetate at the highest doses (5.6 and $8.8 \mu$ moles) was also the most efficacious of the three substances at suppressing lever pressing in an operant schedule of reinforcement that generates very low rates of response, and thus is very difficult to suppress [i.e., the differential-reinforcementof-low-rates-of-responding (DRL) $30 \mathrm{~s}$ schedule, Arizzi et al., 2003].

While in the present experiments acute administration of acetate was demonstrated to suppress locomotion, at least in rats, chronic administration of acetate in the drinking water for 15 days did not change locomotion on its own. Nevertheless, it did reduce ethanol-induced locomotion in the open field (see Figure 3). Thus, chronic pre-exposure to a low dose of acetate made animals more resistant to the stimulating effects of medium doses of ethanol in mice. Acetate, however, does not seem to mediate other ethanol well known effects, such as the anxiolytic response which acetaldehyde has been demonstrated to regulate (Correa et al., 2003, 2008; Escrig et al., 2007, 2012). Acutely administered acetate $(50-200 \mathrm{mg} / \mathrm{kg}$, IP) did not alter the behavior of mice in either the elevated plus maze or the dark and light box (Escrig et al., 2007, 2012). The same pattern of effects was observed in the interior part of an OF (Correa et al., 2003). Acutely administered acetate ICV at doses similar to the present ones $(0.35-2.8 \mu$ moles $)$ did not modify anxiety measures in the open field in rats, although it reduced locomotion (Correa et al., 2003). Moreover, in the present results, mice exposed to acetate for 15 days did not show changes in the anxiolytic response in the dark/light box after ethanol administration. The dose of ethanol used $(1.0 \mathrm{~g} / \mathrm{kg})$ has previously been demonstrated to have a potent anxiolytic effect under the present conditions (Correa et al., 2008; Escrig et al., 2012). Unfortunately, that anxiolytic effect was very mild in the present results, thus we cannot rule out this fact as the lack of interaction. In summary, although acetate has been shown to be involved in the locomotor suppressing effects of ethanol in mice (Israel et al., 1994) and rats (Correa et al., 2003; Arizzi-LaFrance et al., 2004; present results), it does not seem to mediate ethanol's anxiolytic actions (Correa et al., 2003), nor does it seem to be involved in the anxiogenic response produced by a bolus injection of acetaldehyde in the periphery (Escrig et al., 2012).

The higher levels of acetate that accumulate in the brain after repeated administration of ethanol ( $3.5 \mathrm{~g} / \mathrm{kg}$, IP, during 7 days) seem to mediate tolerance to LORR induced by an acute dose of ethanol $(3.5 \mathrm{~g} / \mathrm{kg})$ in outbred rats (Kiselevski et al., 2003). Moreover, there is evidence that higher amounts of acetate are formed in SS rats that have an inborn tolerance to hypnotic doses of ethanol compared to the LS substrain (Zimatkin et al., 2011). In the present studies with mice, the doses achieved 


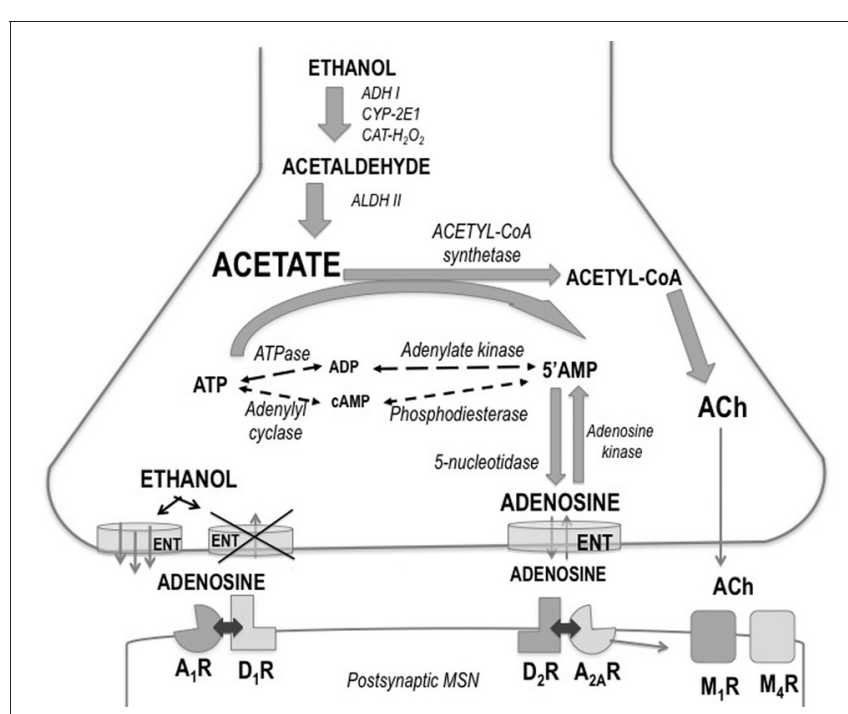

FIGURE 7 | Schematic drawing showing ethanol regulation of adenosine production, release, and uptake in striatum. Abbreviations: $A_{1} R$ and $A_{2 A} R$, adenosine receptors; $A C h$, acetylcholine; $A D H$, alcohol dehydrogenase; $\mathrm{ALDH}$, aldehyde dehydrogenase; ATP, adenosine triphosphate; AMP, adenosine monophosphate; $\mathrm{CAT}-\mathrm{H}_{2} \mathrm{O}_{2}$, catalase; CYP-2E1, cytochrome P4502E1; $D_{1} R$ and $D_{2} R$, dopamine receptors; ENT, equilibrative nucleoside transporters; $M_{1} R$ and $M_{4} R$, muscarinic receptors; MSN, medium spiny neuron.

after consuming water with acetate concentrations of 500 and $1000 \mathrm{mg} / \mathrm{l}$ are significantly lower (around 30 and $65 \mathrm{mg} / \mathrm{kg}$ per day, respectively). Thus, the lack of effects in latency and duration of LORR after acute administration of the high doses of ethanol ( 4.0 and $4.5 \mathrm{~g} / \mathrm{kg}$ ) could be due to the fact that the doses achieved after consuming these concentrations of acetate are significantly lower than the ones used in other studies. Also, these discrepancies in results could be due to species differences; mice been shown to be more resistant than rats to the suppressive effects of ethanol and acetate. However, our results on number of animals achieving LORR (Figure 4) indicate that chronic acetate provides some sort of resistance in mice to the hypnotic effects of ethanol.

The precise brain areas and neural mechanisms through which acetate produces its potent suppression of motor activity are not known. A potential neuroanatomical locus for the locomotor actions of acetate, ethanol and acetaldehyde was previously found (Arizzi-LaFrance et al., 2004, 2006). Acetate injected into the substantia nigra pars reticulata of the mesencephalon produced a slight locomotor suppression (Arizzi-LaFrance et al., 2004) in contrast to the clear stimulation demonstrated for ethanol and acetaldehyde (Arizzi-LaFrance et al., 2006). Concentrations of several neurotransmitters such as acetylcholine (ACh) and adenosine seem to be modulated by the production of acetate. These hypothetical mechanisms are summarized in Figure 7. Acetate has demonstrated to increase the formation of adenosine (Dar et al., 1983; Phillis et al., 1992; Carmichael et al., 1993; Israel et al., 1994; Kiselevski et al., 2003). Ethanol increases adenosine levels by acting as a precursor through the production of acetate
(Orrego et al., 1988; Carmichael et al., 1991). High doses of sub-chronically administered ethanol have been demonstrated to increase acetate, adenosine, and ACh, as well as several other biochemical factors responsible of acetate, in several areas of the brain (Kiselevski et al., 2003). It has also been suggested that ethanol as well as acetate can block adenosine uptake into the neuron (Fredholm and Wallman-Johansson, 1996; Kiselevski et al., 2003; Correa and Font, 2008), thus increasing extra-synaptic adenosine levels. Adenosine has been implicated in multiple behaviors including sleep, arousal, and motor activity (Huston et al., 1996; Iversen et al., 2009). There is evidence that adenosine may contribute to some behavioral effects of ethanol such as sedation, and motor suppression or incoordination (Proctor et al., 1985; Clark and Dar, 1988, 1989; Dar, 1990, 1993, 2000; Carmichael et al., 1991; Meng and Dar, 1995; Campisi et al., 1997; Barwick and Dar, 1998). Motor incoordination induced by ethanol is controlled by adenosine in the striatum and cerebellum (Dar, 1993; Meng and Dar, 1995). Studies also indicate that adenosine receptor activation provides a major contribution to motor suppressant effects of low concentrations of ethanol when the production of acetate is near maximal (Carmichael et al., 1993; Israel et al., 1994). At higher doses of ethanol, such as the ones used in LORR studies, the role of the acetate-adenosine system is proportionately reduced (Israel et al., 1994). As the acetate level increases after high doses of ethanol, the activation of acetyl-CoA synthetase would be expected and the formation of ACh is then potentiated (Kiselevski et al., 2003). Acetate induced increases in ACh in cerebral cortex have been associated to tolerance to ethanol-induced LORR (Zimatkin et al., 2011). Thus, the present results suggest that an increase in $\mathrm{ACh} / \mathrm{adenosine}$ content may be responsible for the effects of acetate on locomotor suppression, and for blocking the stimulation of locomotion induced by ethanol and increasing resistance to achieve LORR. Further studies about the involvement of ACh, adenosine, and their subtype-receptors in these actions of acetate are warranted.

The relevance of the present acetate results (i.e., suppression of locomotion, blockade of ethanol stimulation) is related to the suggestion that two pharmacological effects that may be particularly relevant for alcohol consumption are behavioral stimulation and sedation (King et al., 2002, 2011). In general, doses of ethanol that produce more stimulation are more likely to be consumed. Subjects report that their typical drinking bout is in the dose range that was considered as having activating or disinhibiting effects (King et al., 2002, 2011). Sedative or suppressing effects on activation may also influence drinking behavior; anticipated sedative effects vary inversely with alcohol consumption (Earleywine and Martin, 1993) and heavier drinkers anticipate fewer sedative effects of alcohol than lighter drinkers (O'Malley and Maisto, 1984). Thus, sedative effects seem to prevent self-administration of ethanol, and stimulant effects can foster consumption of this drug. In agreement with these hypotheses, rats do not selfadminister acetate ICV under the same conditions that lead to ethanol or acetaldehyde self-administration (Rodd-Henricks et al., 2002), and acetate does not stimulate locomotion under the same conditions that ethanol and acetaldehyde do (Correa et al., 2003). 


\section{ACKNOWLEDGMENTS}

This research was supported by a grant to Mercè Correa from Plan Nacional de Drogas (2010I024), Spain, and a grant to John D. Salamone from NIH/NIMH (MH078023-01A1), USA. Marta Pardo was funded by a

\section{REFERENCES}

Arizzi-LaFrance, M. N., Correa, M., Aragon, C. M., and Salamone, J. D. (2006). Motor stimulant effects of ethanol objected into the substantia nigra pars reticulata: importance of catalase-mediated metabolism and the role of acetaldehyde. Neuropsychpharmacology 31, 997-1008. doi: 10.1038/sj.npp. 1300849

Arizzi-LaFrance, M. N., Correa, M., and Salamone, J. D. (2004). Locomotor activating effects of ethanol and ethanol metabolites after injection into the substantia nigra pars reticulata: effects of catalase blockade. Alcohol. Clin. Exp. Res. 28, 61A.

Arizzi, M. N., Correa, M., Betz, A. J., Wisniecki, A., and Salamone, J. D. (2003). Behavioral effects of intraventricular injections of low doses of ethanol, acetaldehyde, and acetate in rats: studies with low and high rate operant schedules. Behav. Brain Res. 147, 203-210. doi: 10.1016/S0166-4328(03)00158-X

Barwick, V. S., and Dar, M. S. (1998). Adenosinergic modulation of ethanol-induced motor incoordination in the rat motor cortex. Prog. Neuropsychopharmacol. Biol. Psychiatry 22, 587-607. doi: 10.1016/S0278-5846(98)00025-6

Busch, H. (1953). Studies on the metabolism of acetate-1-C in tissues of tumor-bearing rats. Cancer. Res. 13, 789-794.

Campisi, P., Carmichael, F. J., Crawford, M., Orrego, H., and Khanna, J. M. (1997). Role of adenosine in the ethanol-induced potentiation of the effects of general anesthetics in rats. Eur. J. Pharmacol. 325, 165-172. doi: 10.1016/S0014-2999(97)00124-6

Carmichael, F. J., Israel, Y., Crawford, M., Minhas, K., Saldivia, V., Sandrin, S., et al. (1991). Central nervous system effects of acetate: contribution to the central effects of ethanol. J. Pharmacol. Exp. Ther. 259, 403-408.

Carmichael, F. J., Orrego, H., and Israel, Y. (1993). Acetate-induced adenosine mediated effects of ethanol. Alcohol Alcohol. 2, 411-418.

Chuck, T. L., McLaughlin, P. J., ArizziLaFrance, M. N., Salamone, J. D., and Correa, M. (2006). Comparison between multiple behavioral effects of peripheral ethanol administration in rats: sedation, ataxia, and bradykinesia. Life Sci. 79, 154-161. doi: 10.1016/j.lfs.2005.12.045

Clark, M., and Dar, M. S. (1988). Mediation of acute ethanol-induced motor disturbances by cerebellar adenosine in rats. Pharmacol. Biochem. Behav. 30, 155-161. doi: 10.1016/0091-3057(88)90439-X

Clark, M., and Dar, M. S. (1989). Effect of acute ethanol on release of endogenous adenosine from rat cerebellar synaptosomes. J. Neurochem. 52, 1859-1865. doi: 10.1111/j.14714159.1989.tb07268.x

Correa, M., Chuck, T., Arizzi, M. N., Betz, A., McLaughlin, P. J., and Salamone, J. D. (2003). Motor effects of ethanol and ethanol metabolites after intracranial or peripheral injections in rats. Behav. Pharmacol. 14, 76-77.

Correa, M., and Font, L. (2008). Is there a major role of A2A adenosine receptor in anxiety? Front. Biosci. 1, 4058-4070. doi: 10.2741/ 2994

Correa, M., Manrique, H. M., Font, L., Escrig, M. A., and Aragon, C. M. G. (2008). Reduction in the anxiolytic effects of ethanol by centrally formed acetaldehyde: the role of catalase inhibitors and acetaldehyde-sequestering agents. Psychopharmacol. 200, 455-464. doi: 10.1007/s00213-0081219-3.

Correa, M., Miquel, M., SanchisSegura, C., and Aragon, C. M. (1999). Acute lead acetate administration potentiates ethanol-induced locomotor activity in mice: the role of brain catalase. Alcohol. Clin. Exp. Res. 23, 799-805.

Correa, M., Salamone, J. D., Segovia, K. N., Pardo, M., Longoni, R., Spina, L., et al. (2012). Piecing together the puzzle of acetaldehyde as a neuroactive agent. Neurosci. Biobehav. Rev. 36, 404-430. doi: 10.1016/j.neubiorev.2011.07.009

Correa, M., Sanchis-Segura, C., and Aragon, C. M. (2001). Influence of brain catalase on ethanol-induced loss of righting reflex in mice. Drug. Alcohol. Depend. 65, 9-15. doi: $\quad 10.1016 / S 0376-8716(01)$ 00142-9

fellowship from Fundació Bancaixa-UJI (PREDOC200743), Laura López-Cruz was funded by a fellowship from Ministerio de Educación FPU (AP2010-3793), and Noemí San Miguel was supported by Plan Nacional de Drogas (2010I024).

Cullen, N., and Carlen, P. L. (1992). Electrophysiological actions of acetate, a metabolite of ethanol, on hippocampal dentate granule neurons: interactions with adenosine. Brain Res. 588, 49-57. doi: 10.1016/0006-8993(92) 91343-D

Dar, M. S. (1990). Central adenosinergic system involvement in ethanolinduced motor incoordination in mice. J. Pharmacol. Exp. Ther. 255 1202-1209.

Dar, M. S. (1993). Brain adenosinergic modulation of acute ethanolinduced motor impairment. Alcoho Alcohol. Suppl. 2, 425-429.

Dar, M. S. (2000). Cerebellar $\mathrm{CB}(1)$ receptor mediation of Delta(9)-THC-induced motor incoordination and its potentiation by ethanol and modulation by the cerebellar adenosinergic $A(1)$ receptor in the mouse. Brain Res. 864, 186-194. doi: $\quad$ 10.1016/S0006-8993(00) 02103-X

Dar, M. S., Mustafa, S. J., and Wooles, W. R. (1983). Possible role of adenosine in the CNS effects of ethanol. Life. Sci. 33, 1363-1374. doi: $\quad 10.1016 / 0024-3205(83)$ 90819-6

Earleywine, M., and Martin, C. S (1993). Anticipated stimulant and sedative effects of alcohol vary with dosage and limb of the blood alcohol curve. Alcohol. Clin. Exp Res. 17, 135-139. doi: 10.1111/j.1530 0277.1993.tb00738.x

Escrig, M. A., Pardo, M., Aragon, C. M. and Correa, M. (2007). Anxiogenic effects in mice of peripheral acetaldehyde accumulation. Behav. Pharmacol. 18, 77.

Escrig, M. A., Pardo, M., Aragon, C. M., and Correa, M. (2012) Anxiogenic and stress-inducing effects of peripherally administered acetaldehyde in mice: similarities with the disulfiramethanol reaction. Pharmacol. Biochem. Behav. 100, 404-412. doi: 10.1016/j.pbb.2011.10.002

Fredholm, B. B., and WallmanJohansson, A. (1996). Effects of ethanol and acetate on adenosine production in rat hippocampal slices. Pharmacol. Toxicol. 79, 120-123. doi: 10.1111/j.16000773.1996.tb00254.x
Huston, J. P., Haas, H. L., Boix, F., Pfister, M., Decking, U., Schrader, J., et al. (1996). Extracellular adenosine levels in neostriatum and hippocampus during rest and activity periods of rats. Neuroscience 73, 99-107. doi: $\quad 10.1016 / 0306-4522(96)$ 00021-8

Israel, Y., Orrego, H., and Carmichael, F. J. (1994). Acetate-mediated effects of ethanol. Alcohol. Clin. Exp. Res. 18, 144-148. doi: 10.1111/j.15300277.1994.tb00894.x

Iversen, L. L., Iversen, S. D., Bloom, F. E., and Roth, R. H. (2009). Introduction to Neuropsychopharmacology. New York, NY: Oxford University Press.

King, A. C., de Wit, H., McNamara, P. J., and Cao, D. (2011). Rewarding, stimulant, and sedative alcohol responses and relationship to future binge drinking. Arch. Gen. Psychiatry 68, 389-399. doi: 10.1001/archgenpsychiatry. 2011.26

King, A. C., Houle, T., de Wit, H., Holdstock., L., and Schuster, A. (2002). Biphasic alcohol response differs in heavy versus light drinkers. Alcohol. Clin. Exp. Res. 26, 827-835. doi: 10.1111/j.15300277.2002.tb02611.x

Kiselevski, Y., Oganesian, N., Zimatkin, S., Szutowicz, A., Angielski, S., Niezabitowski, P., et al. (2003). Acetate metabolism in brain mechanisms of adaptation to ethanol. Med. Sci. Monit. 9, 178-182.

Lundquist, F., Tygstrup, N., Winkler, K., Mellemgaard, K., and MunckPetersen, S. (1962). Ethanol metabolism and production of free acetate in the human liver. J. Clin. Invest. 41, 955-961. doi: 10.1172/JCI104574

McLaughlin, P. J., Chuck, T. L. Arizzi-LaFrance, M. N., Salamone, J. D., and Correa, M. (2008). Central vs. peripheral administration of ethanol, acetaldehyde and acetate in rats: effects on lever pressing and response initiation. Pharmacol. Biochem. Behav. 89, 304-313. doi: 10.1016/j.pbb.2008. 01.002

Meng, Z. H., and Dar, M. S. (1995). Possible role of striatal adenosine in the modulation of acute 
ethanol-induced motor incoordination in rats. Alcohol. Clin. Exp. Res. 19, 892-901. doi: 10.1111/j.15300277.1995.tb00964.x

O’Malley, S. S., and Maisto, S. A. (1984) Factors affecting the perception of intoxication: dose, tolerance, and setting. Addict. Behav. 9, 111-120. doi: $\quad 10.1016 / 0306-4603(84)$ 90049-2

Oldendorf, W. H. (1973). Carriermediated blood-brain barrier transport of short-chain monocarboxylic organic acids. Am J. Physiol. 224, 1450-1453.

Orrego, H., Carmichael, F. J., and Israel, Y. (1988). New insights on the mechanism of the alcohol-induced increase in portal blood flow. Can. J. Physiol. Pharmacol. 66, 1-9. doi: 10.1139/y88-001

Phillis, J. W., O’Regan, M. H., and Perkins, L. M. (1992). Actions of ethanol and acetate on rat cortical neurons: ethanol/adenosine interactions. Alcohol 9, 541-546. doi: 10.1016/0741-8329(92)90094-Q

Proctor, W. R., Baker, R. C., and Dunwiddie, T. V. (1985). Differential CNS sensitivity to PIA and theophylline in long-sleep and short-sleep mice. Alcohol 2, 387-391. doi: 10.1016/0741-8329(85)90061-8

Rodd-Henricks, Z. A., Bell, R. L., Kuc, K. A., Murphy, J. M., McBride, W. J., Lumeng, L., et al. (2002). Effects of ethanol exposure on subsequent acquisition and extinction of ethanol self-administration and expression of alcohol-seeking behavior in adult alcohol-preferring (P) rats: II. Adult exposure. Alcohol. Clin. Exp. Res. 26, 1642-1652. doi: $\quad 10.1111 /$ j.1530-0277.2002. tb02466.x

Van den Berg, C. J., Mela, P., and Waelsch, H. (1966). On the contribution of the tricarboxylic acid cycle to the synthesis of glutamate, glutamine and aspartate in brain. Biochem. Biophys. Res. Commun. 23, 479-484. doi: $\quad 10.1016 / 0006-291 X(66)$ 90753-4

Zimatkin, S. M., Oganesian, N. A., Kiselevski, Y. V., and Deitrich, R. A. (2011). Acetate-dependent mechanisms of inborn tolerance to ethanol. Alcohol Alcohol. 46, 233-238. doi: 10.1093/alcalc/agr014 Zimatkin, S. M., Pronko, S. P., Vasiliou, V., Gonzalez, F. J., and Deitrich, R. A. (2006). Enzymatic mechanisms of ethanol oxidation in the brain. Alcohol. Clin. Exp. Res. 30, 1500-1505. doi: 10.1111/j.15300277.2006.00181.x

Conflict of Interest Statement: The authors declare that the research was conducted in the absence of any commercial or financial relationships that could be construed as a potential conflict of interest.

Received: 10 April 2013; accepted: 18 June 2013; published online: 10 July 2013.

Citation: Pardo M, Betz AJ, San Miguel $N$, López-Cruz L, Salamone JD and Correa $M$ (2013) Acetate as an active metabolite of ethanol: studies of locomotion, loss of righting reflex, and anxiety in rodents. Front. Behav. Neurosci. 7:81. doi: 10.3389/fnbeh.2013.00081

Copyright (C) 2013 Pardo, Betz, San Miguel, López-Cruz, Salamone and Correa. This is an open-access article distributed under the terms of the Creative Commons Attribution License, which permits use, distribution and reproduction in other forums, provided the original authors and source are credited and subject to any copyright notices concerning any third-party graphics etc. 